\title{
Bacteria are small but not stupid: cognition, natural genetic engineering and socio-bacteriology
}

\author{
J.A. Shapiro \\ Department of Biochemistry and Molecular Biology, University of Chicago, 929 E. 57th Street, Chicago IL 60637, USA
}

\begin{abstract}
Forty years' experience as a bacterial geneticist has taught me that bacteria possess many cognitive, computational and evolutionary capabilities unimaginable in the first six decades of the twentieth century. Analysis of cellular processes such as metabolism, regulation of protein synthesis, and DNA repair established that bacteria continually monitor their external and internal environments and compute functional outputs based on information provided by their sensory apparatus. Studies of genetic recombination, lysogeny, antibiotic resistance and my own work on transposable elements revealed multiple widespread bacterial systems for mobilizing and engineering DNA molecules. Examination of colony development and organization led me to appreciate how extensive multicellular collaboration is among the majority of bacterial species. Contemporary research in many laboratories on cell-cell signaling, symbiosis and pathogenesis show that bacteria utilise sophisticated mechanisms for intercellular communication and even have the ability to commandeer the basic cell biology of 'higher' plants and animals to meet their own needs. This remarkable series of observations requires us to revise basic ideas about biological information processing and recognise that even the smallest cells are sentient beings.
\end{abstract}

(c) 2007 Elsevier Ltd. All rights reserved.

Keywords: Computation; Sensing; Regulation; Cybernetic; Evolution

When citing this paper, please use the full journal title Studies in History and Philosophy of Biological and Biomedical Sciences

\section{Introduction}

The philosophy of microbiology is not well defined, at least for practicing microbiologists like me. If we think about it, I suppose most microbiologists see microorganisms as constituting a special branch of living organisms. Some, like myself, appreciate microbial virtuosity and emphasize the essential role microorganisms play in maintaining the biosphere and carrying out the bulk of energetic and geochemical transformations on the planet (Lovelock \& Margulis, 1974; Lenton \& van Oijen, 2002). Others follow conventional wisdom and think of microbes as 'lower' forms of life, simpler and less capable than eukaryotes because of their smaller size and apparent lack of internal cellular structure. The conventional wisdom is an extension of the mechanistic views that came to dominate biological thought in the early years of the twentieth century. The idea is that microbes, particularly prokaryotes, exemplify the basic properties of living cells reduced to their simplest configurations. The goal of researchers who subscribe to this view is to find or construct the minimal living organism (Luisi et al., 2006).

Molecular biology came into being on the promise of confirming mechanistic views of life by defining how living cells worked at a physico-chemical level (Judson, 1979). Ironically, molecular biology has uncovered a vast realm

E-mail address: jsha@uchicago.edu 
of complex intracellular machinery, signal transduction, regulatory networks and sophisticated control processes that were unanticipated in the early days of this new approach to life (Alberts et al., 2002). Increasingly, computational rather than mechanical models are invoked to account for the operation of subcellular systems, the cell cycle, cellular differentiation, and the development of multicellular organisms (Bray, 1990, 1995; Gearhart \& Kirschener, 1997).

My own view is that we are witnessing a major paradigm shift in the life sciences in the sense that Kuhn (1962) described that process. Matter, the focus of classical molecular biology, is giving way to information as the essential feature used to understand how living systems work. Informatics rather than mechanics is now the key to explaining cell biology and cell activities. The traditional mechanistic view held that the structure of biological molecules determines the actions of cells in some kind of linear fashion. But today we know that biological molecules change their structures as they interact with other molecules and that these structural changes contain information about the external environment and conditions within the cell. As illustrated below, we have abundant results showing that what a cell does is a function of the information it has about itself and its surroundings (i.e. about past molecular interactions). Much contemporary research aims to understand how cellular processes are controlled adaptively to guarantee survival and reproduction in response to the millions of molecular events that occur in each cell cycle. This informatic approach is richer than a mechanistic one because it allows us to discuss complex, non-linear, goal-oriented processes with all kinds of feedbacks and decision points. (See O'Malley \& Dupré, this section, for further discussion about the inadequacy of mechanistic thinking).

Bacteria are full participants in this biological paradigm shift, and the recognition of sophisticated information processing capacities in prokaryotic cells represents another step away from the anthropocentric view of the universe that dominated pre-scientific thinking. Not only are we no longer at the physical center of the universe; our status as the only sentient beings on the planet is dissolving as we learn more about how smart even the smallest living cells can be.

\section{Personal history: transposable elements, adaptive mutation and bacterial colony development}

It is impossible to explain a scientific viewpoint without incorporating the personal history of observations and ideas that leads to a particular way of thinking. So I hope the readers of this symposium will indulge me in a short autobiographical sketch of my career as bacterial geneticist and microbiologist.

In the fall of 1964, I arrived in Cambridge, England, with a Marshall Scholarship from HM Government intending to read Part II Biochemistry and then return to the US to study medicine. I had just graduated college with a B.A. in English Literature and felt that I needed more exposure to biology than I received in the minimal premed courses I had taken. However, the Part II Biochemistry course was full that year, and I ended up doing research in the Genetics Department on mutation in bacteria. My research topic led me to get advice and strains from Sydney Brenner at the Medical Research Council (MRC) Laboratory of Molecular Biology. These contacts introduced me to the challenging and exciting world of molecular genetics, then focused primarily on prokaryotic systems. Later, to complete my Doctoral research, I moved to the MRC Microbial Genetics Research Unit (MGRU), headed by Bill Hayes at Hammersmith Hospital in London.

The mid 1960s were a heady time of revolutionary discoveries about basic cellular processes defined in molecular terms. The black box of prokaryotic cell biology had opened, and the scientific community was defining the components of systems underlying metabolism, protein synthesis, DNA replication and DNA transfer. Of particular importance to me were three topics related to my research and that of my lab mates. The review summarizing regulation of the lac operon by Jacob and Monod (1961) had recently been published, defining a whole new class of genomic elements: cis-acting sites recognized by proteins regulating transcription. Allan Campbell (1962) had just proposed his model for insertion and excision of phage lambda DNA in and out of the bacterial genome, and research was beginning to extend the 'Campbell Model' by identifying the special sites and proteins that carry out this particular case of what was then called illegitimate recombination. Finally, Naomi Datta and Elinor Meynell at MGRU were extending the work of Tsutomu Watanabe (1963) by examining the plasmids that encoded the resistances bacteria had evolved to counter widespread antibiotic chemotherapy (Meynell \& Datta, 1967). The bacterial genetics all around me had little to do with the classical genetics developed in the first half of the twentieth century, before we knew about DNA, or before many people believed that bacteria had any genetics at all.

My own Ph.D. research ended up focusing on some unusual mutations that I mapped and characterized in the E. coli gal operon (Adhya \& Shapiro, 1969; Shapiro $\&$ Adhya, 1969). These mutations were located in coding regions, blocked expression of downstream cistrons, mapped like point mutations, and reverted spontaneously. In all these properties, they resembled certain polar basechange mutations of the lac operon (Newton et al., 1965), but my mutations could not be induced to revert at higher frequencies by base-substitution or frameshift mutagens. Instead of being point mutations or deletions, I hypothesized in my thesis that they resulted from insertion of additional DNA into the operon (Shapiro, 1968). I was able to confirm this hypothesis during my postdoctoral year at the Institute Pasteur by density gradient analysis of wild type and mutant operons cloned in lambda-gal particles (Shapiro, 1969; see Cohen \& Shapiro, 1980, for a 
non-technical summary). Later analysis showed that the same pieces of DNA inserted into other $E$. coli operons and identified them as transposable 'insertion sequences', or IS elements (Mahillon \& Chandler, 1998).

At the tender age of twenty-five, I had encountered transposable elements for the first time. Such mobile elements had no place in conventional Mendelian genetics. But it quickly became apparent at a meeting I organized with Ahmed Bukhari and Sankhar Adhya at Cold Spring Harbor Laboratory in May of 1976, that transposable and other mobile genetic elements were virtually ubiquitous in prokaryotic and eukaryotic genomes (Bukhari, Shapiro \& Adhya, 1977). At that meeting, I initiated two friendships which greatly influenced my thinking. One of these was with Arianne Toussaint and Michel Faelen from the Free University of Brussels, who studied DNA rearrangements mediated by bacteriophage $\mathrm{Mu}$, a virus that uses transposition to replicate its genome (Toussaint et al., 1994). Thinking about $\mathrm{Mu}$ helped me work out one of several related transposition mechanisms used by bacterial transposons (Shapiro, 1979). The profound differences and the profound similarities between the insertion mechanisms of Lambda and $\mathrm{Mu}$ taught me that organized protein-DNA complexes can carry out virtually any genome restructuring process compatible with the physical chemistry of DNA molecules. The real world significance of this lesson has been abundantly confirmed over the years in systems ranging from bacterial plasmid and chromosome evolution to the mammalian immune system (Craig et al., 2002). Surprises about the versatility of DNA rearrangement mechanisms still keep appearing (MacDonald et al., 2006).

The second friendship initiated at that 1976 Cold Spring Harbor meeting was with Barbara McClintock, who had discovered transposable elements three decades earlier through rigorous cytogenetic analysis of maize plants (McClintock, 1987). Educated at the start of the twentieth century, when genetic concepts were still in the formative stage, Barbara was a pioneering cytogeneticist with an organic view of genome operations and a fierce independence of thought. She preferred to believe what her maize plants taught her rather than what her colleagues told her should be so. Somehow, I had the good sense to realize that Barbara was a rare master scientist who had much wisdom to communicate. So I spent over a decade in visits and long telephone calls trying to learn what ideas she had distilled from her research and extensive knowledge of the natural world.

One of Barbara's key insights is that living cells have the systems in place to repair and restructure their genomes. This insight fit perfectly with my own studies of transposition mechanisms as well as with my experience doing in vivo cloning of the $E$. coli lac operon in lambda phages when I was a postdoc in Jon Beckwith's laboratory (Shapiro et al., 1969). In a review published shortly before Barbara's death, I placed all these restructuring processes under the rubric 'natural genetic engineering' (Shapiro, 1992a), a name that incorporates the sense of purposeful action by cells under challenge that she described in her Nobel Prize address (McClintock, 1984). The idea of natural genetic engineering is controversial to some because it implies the existence of an engineer to decide when restructuring should occur. (Indeed, one journal editor would not publish a paper of mine earlier this year because I insisted on using the phrase). But natural genetic engineering fits very well with a more contemporary view of cells as cognitive entities acting in response to sensory inputs.

I was fortunate a few years later when my fascination with phage $\mathrm{Mu}$ led me to demonstrate DNA restructuring in response to physiological stress. My colleague Malcolm Casadaban had developed a technique using $\mathrm{Mu}$ to generate hybrid fusion proteins in vivo (Casadaban, 1976), and my former Ph.D. student, Spencer Benson, piqued my interest in the fusion process when he told me it required thick agar plates because the fusion colonies only appeared after long periods of incubation. After failing to persuade Spencer to study this phenomenon, I undertook the subject myself and quickly found evidence that selection on the appropriate growth medium triggers a frequent $\mathrm{Mu}$-dependent fusion process (found in over one in every $10^{5}$ cells), which was undetectable during normal growth (found in fewer than one in every $10^{10}$ cells; Shapiro, 1984a). This was the first example of the phenomenon later called 'adaptive' or 'stress-induced' mutation (Shapiro, 1997; Rosenberg, 2001). Further research with Genevieve MaenhautMichel, David Leach and colleagues from the Brussels $\mathrm{Mu}$ group confirmed the role of $\mathrm{Mu}$ transposition functions in forming hybrid proteins, allowed us to formulate a molecular model, and demonstrated that aerobic carbohydrate starvation stimulated regulatory proteins to activate the fusion process (Maenhaut-Michel \& Shapiro, 1994; Shapiro, 1997; Lamrani et al., 1999). The older I became, the more my experiences with genetic change in bacteria deviated from the conventional wisdom. Fortunately, my results fit with precedents from plant genetics, where researchers had documented that various stresses also activate transposable elements (McClintock, 1984, 1987; Wessler, 1996).

While I was studying the formation of protein fusions, I recorded the daily appearance of colonies photographically. After learning about a new high resolution film, I also happened to take photos of sectored colonies made with one of Casadaban's other $\mathrm{Mu}$ derivatives for in vivo genetic engineering. When I developed the prints, I saw that every colony was organized like a flower and displayed many patterns like those that McClintock had observed in her maize kernels (Shapiro, 1984b, c, 1992c; see Fig. 1). Pat Higgins and I subsequently found that some of these patterns resulted from differential activation of $\mathrm{Mu}$ transposition/replication functions (Shapiro \& Higgins, 1989). Suddenly, the differences between maize plants and bacterial colonies were dissolving, and it became apparent to me that bacterial colonies could also be viewed as multicellular organisms (Shapiro, 1988). 


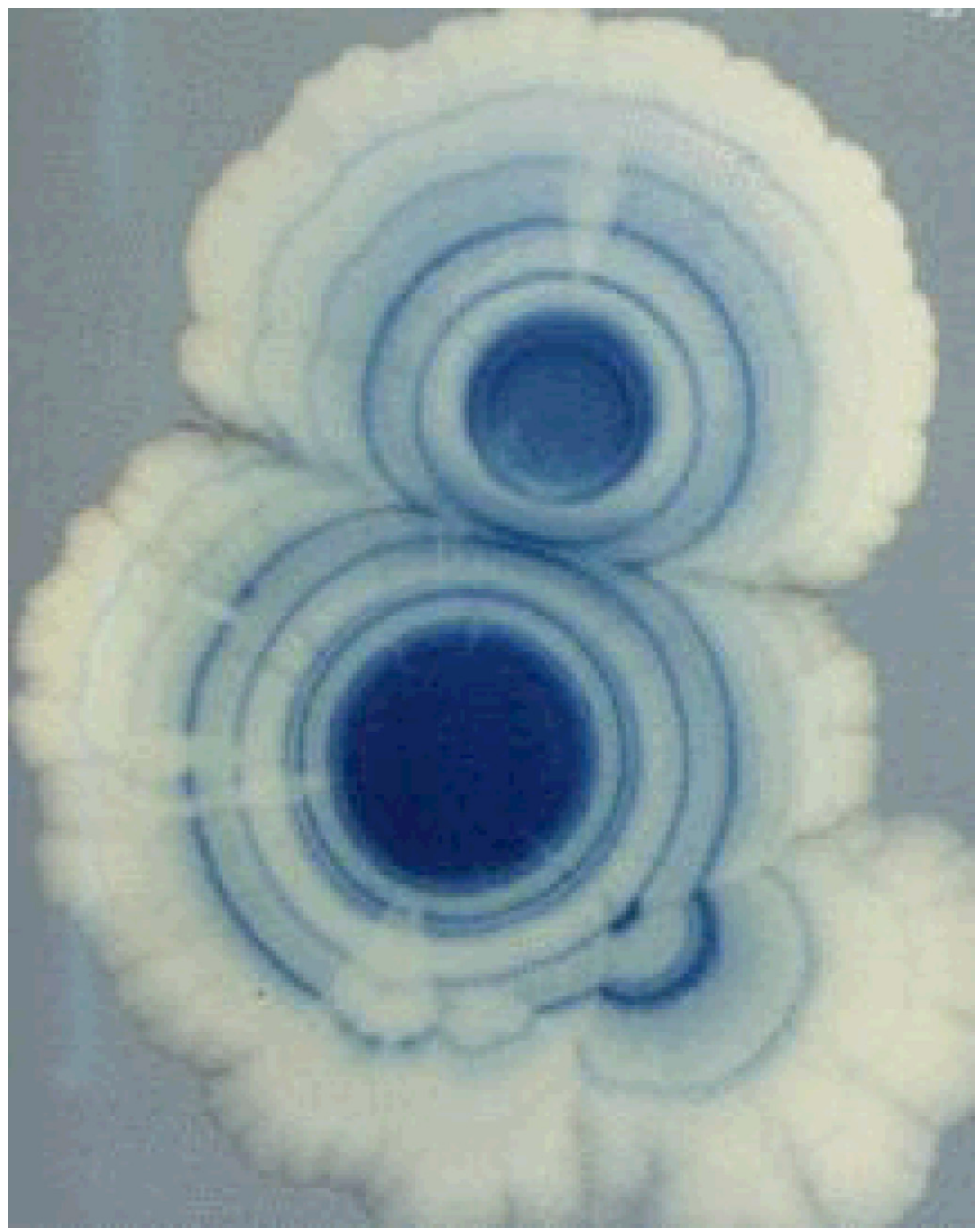

Fig. 1. Two adjacent $E$. coli colonies growing on medium where expression of a particular protein leads to deposition of blue dye. Note the rings and sectors (wedges) where expression differs.

My own work with bacterial colonies concentrated on documenting patterns and developmental events involving cell differentiation and cell-cell interaction. One could see with the scanning electron microscope that $E$. coli cells change considerably with respect to size, shape, and how they arrange themselves in local populations during the course of colony morphogenesis (Shapiro, 1987). By light microscopy, it was possible to visualize cell-cell interactions showing that $E$. coli grow on agar surfaces by maximizing contact between cells rather than individual access to substrate (Shapiro \& Hsu, 1989). Despite dense populations, E. coli divide just as rapidly on agar as they do in well aerated suspension cultures (Shapiro, 1992b). Evi- dently, these bacteria had evolved to grow in a group environment, not as isolated individuals (i.e. 'single cell organisms'), and they had acquired the capacity to form organized groups of differentiated cells.

A related species of enteric bacteria, Proteus mirabilis, attracted my attention because it is famous for collective movement over agar surfaces, known as swarming. Studies with Proteus indicated that overall colony patterns (see Fig. 2) reflect the operation of highly regular systems for cell differentiation and motility (Rauprich et al., 1996; Esipov \& Shapiro, 1998). It is important to note that the strikingly symmetrical colony structure apparently does not have any intrinsic functionality. Swarming motility is 


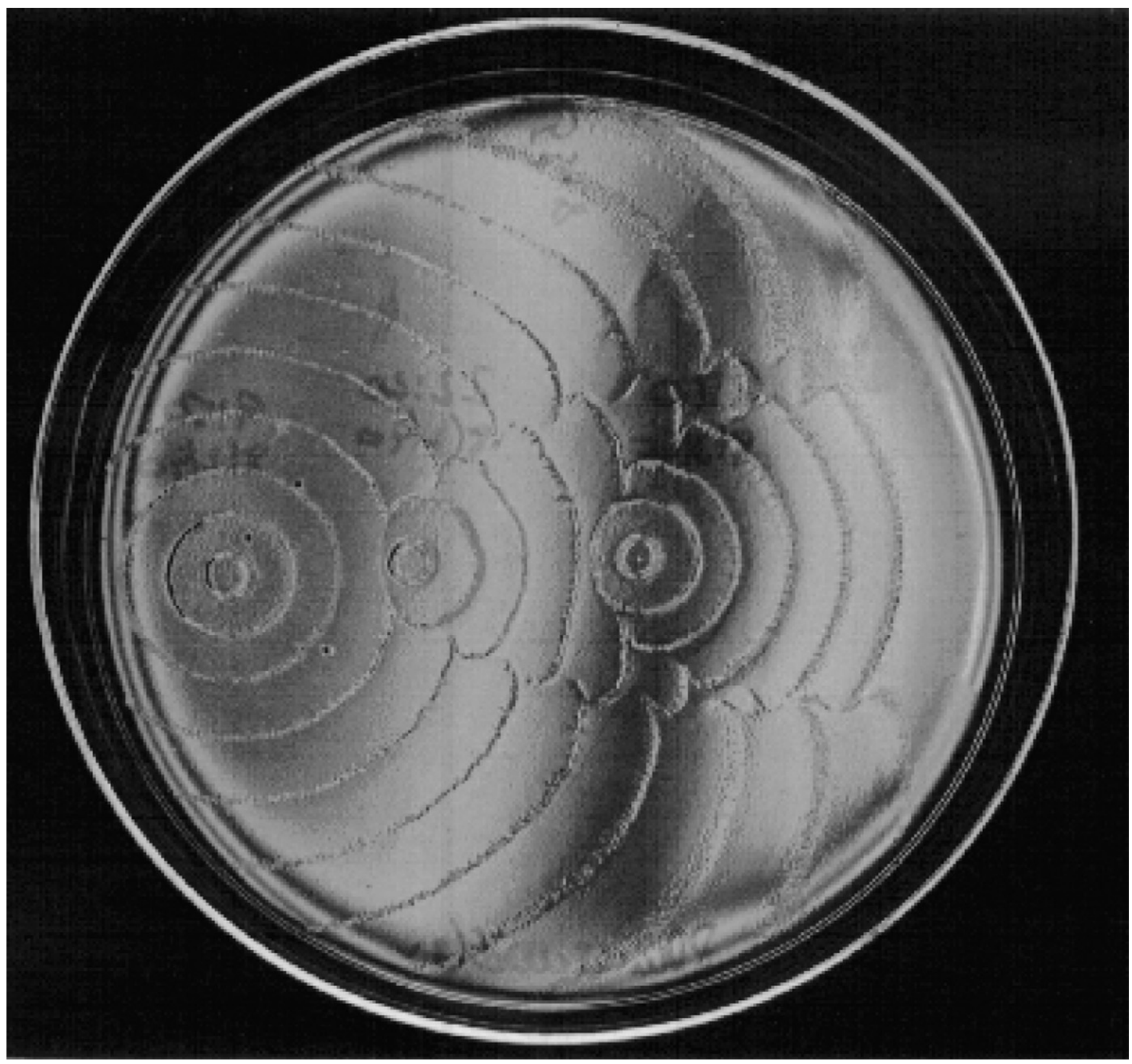

Fig. 2. Intersecting swarm colonies of Proteus mirabilis. The three spots show where the bacteria were inoculated at the start of growth (a different time for each spot). The terraces show the results of periodic spreading over the medium. The fact that the terraces do not merge when they touch indicates that periodicity results from processes internal to each colony.

adaptive howeverer, because it gives the bacteria access to additional nutrients. In other words, seeing pattern and organization in bacterial colonies tells us that bacteria engage in regulated, coordinated behaviors, even when the biological utility of group activity may be something quite different from colony morphogenesis.

As I was pursuing my studies of bacterial multicellularity, I had the good fortune to make another important friend: Martin Dworkin from the University of Minnesota. Marty is the microbiologist who tamed Myxococcus xanthus so that it could be studied in the laboratory (Dworkin, 1962). The Myxobacteria engage in group predation-hunt- ing in packs and lysing prey microorganisms-and they produce such elaborate multicellular fruiting bodies when they sporulate that they were originally classified as fungi (Dworkin, 2000; Kaiser, 1993). In 1983, Marty published one of the great unheralded papers in microbiology, where he demonstrated that packs of $M$. xanthus cells could detect and migrate towards chemically inert beads (Dworkin, 1983). In the 1990s, Marty and I organized a couple of meetings at Woods Hole Marine Biological Laboratory on bacterial multicellularity and in 1997, we published the first book on Bacteria as multicellular organisms (Shapiro \& Dworkin, 1997). This organizing and editorial work 
exposed me to multiple examples of 'sociobacteriology' and taught me to appreciate bacterial multicellularity in natural environments.

\section{Bacterial cognition in cybernetics and nanofabrication}

In drawing general conclusions, it is always necessary to ask yourself whether your own experience is somehow exceptional and/or biased. When I began my research on transposable elements, adaptive mutation, and bacterial colonies, many of my colleagues felt that these topics were deviations from basic microbiological phenomena. Over time, however, the ubiquity and importance of natural genetic engineering and multicellular behavior of bacteria have become widely apparent. Many other microbiologists have documented the unexpected capacities bacteria display for control of their genomes and for meaningful intercellular communication. So let us review some of the observations that fit into a new, more cognitive mode of scientific thinking about bacteria and other living cells. Here the term cognitive refers to processes of acquiring and organizing sensory inputs so that they can serve as guides to successful action. The cognitive approach emphasizes the role of information gathering in regulating cellular function. Discussion of a few examples will show in detail how this perspective applies to bacterial function.

The first point is to recognize that bacteria are far more sophisticated than human beings at controlling complex operations. The fast growing bacterial cell is the ultimate just-in-time production facility. When an $E$. coli cell divides every twenty minutes, exquisitely reliable coordination has been achieved for hundreds of millions of biochemical reactions and biomechanical events. E. coli cells replicate their DNA at almost 4000 base pairs per second, but have an error frequency of far less than one nucleotide misincorporation per every genome duplication (i.e. $2 \times 4.6$ million base pairs are duplicated every forty minutes; Cooper \& Helmstetter, 1968; http://www.genome.wisc.edu/index.html). This incredible precision is accomplished not by rigid mechanical precision but rather by using two layers of expert error monitoring and correction systems: (1) exonuclease proofreading in the polymerase itself, which catches and corrects over $99.9 \%$ of all mistakes as soon as they are made (Kunkel \& Bebenek, 2000), and (2) the methyl-directed mismatch repair (MMR) system, which subsequently detects and fixes over $99 \%$ of any errors that escaped the exonuclease (Modrich, 1991). Together, this multilayered proofreading system boosts the $99.999 \%$ precision of the polymerase to over $99.99999999 \%$. At both stages of the error correction process, detailed molecular analysis has clarified the distinct roles of sensory and repair components. In the case of the MMR system, the sophistication is even more impressive because the molecules discriminate newly replicated from old DNA so that they only correct the newly synthesized strand (Radman \& Wagner, 1988).

The combination of cognition (error detection) and response (error correction) exemplified by DNA replication proofreading is paradigmatic for a wide variety of bacterial processes. Bacteria constantly pick up information from inside and outside the cell and function adaptively, based on what they have sensed. Another key example dates back to pre-molecular days, when Jacques Monod (1942) demonstrated that $E$. coli can discriminate between the sugars glucose and lactose. The molecular biology underlying this discrimination is now well known and serves as the basis for understanding how cells express genomic protein coding information. Although lactose metabolism is generally described within a mechanical context, it is more useful today to take a computational and cognitive perspective (see Table 1; Shapiro, 2002b). Among E. coli's interactions with the two sugars, there are several cognitive steps: the LacY and LacZ proteins act as lactose sensors; LacI acts as a sensor for the sugar allolactose (i.e. processed lactose); membrane transport protein IIA ${ }^{\text {Glc }}$ acts as an external glucose sensor; and the Crp protein acts as a sensor for cAMP second messenger molecules. The information from all these sensors feeds into a computational network that includes the lac operon regulatory signals so that the cell can compute the following non-trivial Boolean proposition: 'IF lactose present AND glucose NOT present AND cell can synthesize active LacZ and LacY, THEN transcribe lac $Z Y A$ from lacP'. Here, the term compute applies to the evaluation of sensory inputs about glucose and lactose to direct action by the cellular transcription apparatus. Although there is no sharp dividing line between cellular cognition and computation, the first term applies mostly to upstream sensory operations and the second chiefly to functional decisions based on cognitive inputs.

Once properly oriented in our thinking, we can find cognitive and computational phenomena in many of the classic bacterial systems subject to molecular scrutiny. For example, it has long been customary to draw comparisons between bacterial chemotaxis and the operation of a neurosensory system (Adler, 1966; Koshland, 1980), and the chemotaxis control circuit serves as a paradigm of biological computing (Bray et al., 1993). Through interlocking cytoplasmic feedback loops and receptor interactions in the cell membrane, E. coli chemotaxis achieves remarkable functional bandwith; the system is able to guide bacterial swarming over chemical concentration gradients of more than six orders of magnitude (Bray, 2002). Bacteria use chemotaxis to find nutrients, avoid toxic chemicals, sense $\mathrm{pH}$, and interact with host organisms in symbiosis and pathogenesis. So there can be little question about the functionality and adaptiveness of this cognitive system. Similarly, cognition and information processing play essential roles in damage and accident repair. In the SOS response to DNA damage or replication fork failure, the RecA protein functions as a sensory microprocessor. RecA monitors the accumulation of single stranded DNA and derepresses expression of SOS repair functions in response to such accumulation (Witkin, 1991; Sutton et al., 2000). Once the SOS system has been activated, sensory and 
Table 1

Molecular processes in lac operon regulation as Boolean statements (Shapiro, 2002a)

Operations involving lac operon products:

- LacY + lactose(external) $\Rightarrow$ lactose(internal)

- LacZ + lactose $\Rightarrow$ allolactose (minor product)

- $\mathrm{LacI}+\mathrm{lac} O \Rightarrow$ LacI-lacO (repressor bound, lacP inaccessible)

- LacI + allolactose $\Rightarrow$ LacI-allolactose (repressor unbound, lacP accessible)

Operations involving glucose transport components and adenylate cyclase:

- IIA ${ }^{\text {Glc }}-\mathrm{P}+$ glucose $($ external $) \Rightarrow$ IIA ${ }^{\text {Glc }}+$ glucose-6-P(internal)

- IIA ${ }^{\mathrm{Glc}}$-P + adenylate cyclase(inactive) $\Rightarrow$ adenylate cylase(active)

- Adenylate cyclase(active) $+\mathrm{ATP} \Rightarrow \mathrm{cAMP}+\mathrm{P} \sim \mathrm{P}$

Operations involving transcription factors:

- $\mathrm{Crp}+\mathrm{cAMP} \Rightarrow \mathrm{Crp}$-cAMP

- Crp-cAMP $+C R P \Rightarrow$ Crp-cAMP-CRP

- RNA Pol + lacP $\Rightarrow$ unstable complex

- RNA Pol + lacP + Crp-cAMP-CRP $\Rightarrow$ stable transcription complex

Partial computations:

- No lactose $\Rightarrow$ lacP inaccessible

- Lactose + LacZ(basal $)+$ LacY $($ basal $) \Rightarrow$ lacP accessible

- Glucose $\Rightarrow$ low IIA ${ }^{\text {Glc }}$-P $\Rightarrow$ low cAMP $\Rightarrow$ unstable transcription complex

- No glucose $\Rightarrow$ high IIA ${ }^{\text {Glc }}$-P $\Rightarrow$ high cAMP $\Rightarrow$ stable transcription complex

$(1,2,4)$

$(5,6,7,10)$

$(5,6,7,8,9,11)$

information-processing routines (now called checkpoints) come into play to make sure that cell division and DNA replication do not resume until genomic damage has been repaired (Weinert \& Hartwell, 1993).

More intricate kinds of sensing occur in the biogenesis (nanofabrication) of complex structures, such as the helical flagella that propel bacteria as they swim through fluid environments. There are dedicated proteins that 'usher' components of each new flagellum in a properly unfolded state for transport to the external tip of the growing structure, where the components are incorporated and extend the helical filament. When flagellar biogenesis is complete, the ushers can no longer deliver the components, so they convert themselves into transcriptional repressors to shut down synthesis of the now superfluous polypeptides (Aldridge \& Hughes, 2002). The bacterial cell uses the multifunctional usher/repressor proteins to sense the completion of a morphogenetic process and integrate it with genome expression. Note here, as in the case of lac regulation (Table 1), how operational molecules (ushers, transporters, enzymes) have informatic roles as well. There is no Cartesian dualism in an E. coli cell.

\section{Bacteria as natural genetic engineers}

The first focus of my dialogue with bacteria was the study of mutation in the gal operon, to inquire how E. coli cells change their genomes. Their basic response to my inquiry can be summarized as: 'Look at how we can move DNA around.' I was far from the only microbiologist to receive this message. Molecular genetics began with the study of transformation in gram-positive bacteria - the ability of bacterial cells to incorporate information from exogenous DNA - and this was where we first learned about DNA as hereditary material (Avery et al., 1944). My thesis advisor, Bill Hayes, established his repu- tation by showing how autonomous plasmids can promote DNA transfer between bacterial cells (see Hayes, 1968). Joshua Lederberg's students, Norton Zinder and Larry Morse, showed that bacterial viruses could carry genetic information from one cell to another and sometimes even clone pieces of the bacterial chromosome (ibid.). As an illustration of how well integrated these DNA transfer systems are into bacterial life cycles, a recent paper demonstrates that the competence (DNA uptake) system of $V$. cholerae is activated by exposure to chitin, the material composing crustacean exoskeletons, where Vibrio biofilms grow during the marine phase of this organims's life-cycle (Meibom et al., 2005).

Nowhere has bacterial virtuosity in manipulating DNA molecules been more apparent than in the response to the onslaught of antibiotics in medicine and agriculture after World War II. This episode constitutes the most thoroughly documented case of evolutionary change known to us. When antibiotic chemotherapy began on a large scale, there was a well established theory of how bacteria could evolve resistance: mutations would change cell structures so the cells were no longer sensitive to antibiotic action or so the antibiotic could not enter the cell to reach its target. Even though a single mutation might confer only partial resistance, successive mutations would confer ever higher levels. For the philosophers of science, it is important to remember that this theory was abundantly confirmed by laboratory experiments (summarized in Hayes, 1968). Nonetheless, this experimentally confirmed theory was wrong for the vast majority of antibiotic resistant bacteria found in hospitals around the world.

Naturally acquired antibiotic resistance is generally due to the expression of new functions for inactivating antibiotics or for pumping them out of the cell (Foster, 1983). Sometimes, the resistance mechanism involves chemical modification of a cellular antibiotic target so that it is 
rendered insensitive. In the vast majority of cases, resistance arose from acquisition of additional functions by the bacteria, and these functionalities were encoded by plasmids, phages and transposable elements, often including the kind of IS elements I discovered in the gal operon (Watanabe, 1963; Bukhari et al., 1977; Shapiro, 1983; Craig et al., 2002). There can be no doubt that bacteria received evolutionary benefits by having mobile pieces of DNA in their genomes and systems for transferring DNA from cell to cell.

With complete genome sequencing, our appreciation of the role of natural genetic engineering in bacterial evolution has grown tremendously. We know that operons encoding multiple antibiotic resistances are built up by lambda-like integration systems called integrons (Hall \& Collis, 1995). Integrons expand and contract by the insertion and excision of single protein coding sequence cassettes. Integrons are not limited to antibiotic resistance determinants. A large 'super-integron' encoding pathogenicity determinants was discovered in the genome of Vibrio cholerae (Mazel et al., 1998), and diverse bacteria have integrons or sequences for the integrase protein that mediates cassette insertion and excision (Holmes et al., 2003). The functional significance of the cassettes in these novel integrons is not known, but less than 5\% show similarity to antibiotic resistance functions (ibid.).

A related characteristic of bacterial genomes is the presence of large DNA segments that extend tens of kilobases and are clearly distinct from the surrounding genomic DNA in base composition. These segments have been most intensively studied in disease organisms, where they contain coding sequences for virulence functions and are thus called pathogenicity islands (Dobrindt et al., 2004). The base composition differences with the rest of the chromosome indicate that these islands have been imported from other species. In addition to pathogenesis, islands have been described encoding adaptive functions as diverse as magnetotaxis, symbiosis, exoenzyme production, xenobiotic degradation, and toxicity to insects (Dobrindt et al., 2004; Ullrich et al., 2005). Pathogenicity islands and the magnetosome island apparently are products of the kinds of natural genetic engineering studied in the laboratory (Osborne \& Boltner, 2002). Some are flanked by IS elements, some encode integron-like integrases, and others show signs of resulting from bacteriophage-like site-specific integration events. The magnetosome island is rich in IS elements and suffers frequent stress induced deletions by IS activity (Ullrich et al., 2005).

Genomic data reveal that bacteria can use natural genetic engineering systems to acquire large segments of DNA encoding complex adaptive functions from other species. This is basically a more detailed version of Sonea and Panisset's idea that there is one large distributed bacterial genome, from which genomes adapted to particular niches assemble by transfer and integration of DNA segments from different cells into one particular cell type (Sonea \& Panisset, 1983; Sonea \& Mathieu, 2001).
To fill out our picture of bacteria as sophisticated natural genetic engineers, we should note how often these small cells use DNA rearrangements to regulate protein synthesis or to manipulate the structure of the proteins they produce. Table 2 indicates some well studied cases. Interestingly, these examples all involve external proteins where structural changes are important to avoid immune recognition, to change surface attachment properties, or to permit interactions with different cell types. It is also noteworthy that bacterial DNA restructuring and protein engineering involve two features often thought to be limited to 'higher' organisms: repeat DNA sequences (Shapiro, 2002c) and reverse transcription (Doulatov et al., 2004).

The realization that most DNA changes in bacteria (and eukaryotes too) occur by the action of natural genetic engineering systems removes the source of variation in the genome from the category of stochastic events or unpredictable accidents, and places it in the context of cellular biochemistry. This reclassification has major conceptual consequences because cellular biochemistry is subject to regulation and operates in predictable ways. Regulation means that DNA changes are non-random with respect to time, physiology and life history. My own encounter with this reality involved the activation of $\mathrm{Mu}$-dependent fusions (Shapiro, 1984). Other bacterial geneticists have documented stress induced mutagenesis involving point mutations (Rosenberg, 2001) as well as transposable elements (Hall, 1998, 1999; Ilves et al., 2001; Hõrak et al., 2004). Bacteria certainly can use their cognitive capacities to activate DNA change when it can be useful in overcoming selective challenges.

The structural predictability of biochemical processes is a further source of genomic non-randomness in DNA change. Transposases, recombinases and nucleases all have sequence recognition specificities, and there is even a well documented example of reverse splicing in bacteria guided by RNA:DNA sequence recognition (Mohr et al., 2000). Thus, the DNA segments that move through the genome, the places they move, and the sequences they rearrange can have both flexibility and predictability. Ironically, we often understand more about this predictability in eukaryotes than we do in bacteria (Shapiro, 2005). Although we remain ignorant about the full extent of connections between cognitive inputs and evolutionary DNA rearrangements in bacteria, we now can begin to explore this hitherto taboo subject in precise molecular terms.

Table 2

DNA rearrangements controlling protein synthesis and protein structure in bacteria

1) flagellar phase variation in Salmonella (Zieg at el., 1977)

2) fimbrial phase variation in E. coli (Blomfield, 2001)

3) Borrelia VSG expression (Barbour et al., 2000)

4) R64 plasmid sex pilus structure changes (Gyohda et al., 2004)

5) Neisseria pilus and opacity protein changes (Saunders et al., 2000)

6) Bordetella reverse transcriptase (Doulatov et al., 2004) 


\section{Bacteria as masters of cell-cell interactions}

When a discovery such as natural genetic engineering leads us to ask basic conceptual questions that were once inadmissible, it takes time for the new perspective to be widely accepted. However, genome sequencing indicates that the ability of bacteria to carry out sophisticated DNA engineering is likely to prove a minor surprise. Other well documented phenomena imply even greater abilities that bacteria use to reorganize themselves in evolution. Genome sequencing results have clearly established bacterial endosymbiosis as a major aspect of evolution (see Sapp, this issue). The descent of mitochondria from alpha proteobacteria and of chloroplasts from cyanobacteria is generally accepted (Gray, 1999). Less widely known are sequence data supporting at least two other major symbiotic events in the history of life as we know it: (1) the generation of Gram-negative bacteria from symbiosis between an archaea and a Gram-positive bacterium (Gupta, 1998, 2000); and (2) the generation of the first eukaryotic cell from symbiosis between an archaea and a Gram-negative bacterium (Gupta, 2000; Rivera \& Lake, 2004; Horiike et al., 2001, 2004; Embley \& Martin, 2006). If we think about how these important events might have occurred at the molecular level, we have to recognize the tremendous challenges presented by the need to integrate separate genomes, metabolisms, envelopes and external structures into a viable cell. Orchestrating all the required molecular processes makes DNA restructuring look simple in comparison.

Symbiosis demands an ability to coordinate processes in distinct cell types. In recent years, we have begun to learn about one aspect of cellular coordination: how bacteria carry out intercellular communication. The lessons provide us with conceptual tools that expand our ideas about intercellular and multicellular information processing. The first of these tools is the ability to think functionally about bacterial activity at the population rather than the single cell level. My introduction to this perspective was recognizing organized patterns of differential action in colonies (Shapiro, $1984 b, c)$. A related major focus of contemporary bacterial studies is the actions of biofilms, which are thin colonies spread over a surface (Stoodley et al., 2002; Webb et al., 2003; Parsek \& Fuqua, 2004; Branda et al., 2005). It is now widely recognized that multicellularity provides important advantages for pathogens in initial colonization and protection against host defenses (Costerton et al., 1999; Davies, 2003). Biofilms, colonies and aggregates are also important in environmental and industrial microbiology. Many bio(geo)chemical transformations can only be carried out by consortia that couple energetically feeble, single cell processes into thermodynamically robust changes with large overall drops in free energy. Examples include anaerobic transformations in bioreactors, degradation of xenobiotics, and redox coupling of organisms isolated in culture as inseparable multispecies consortia (Schink, 2002; Hoffmeister \& Martin, 2003; Spiegelman et al., 2005). It has been proposed that just this kind of metabolic consortium was the progenitor of the first eukaryotic cells (Margulis et al., 2000).

A particular role for intercellular communication occurs in cellular differentiation during bacterial spore formation. The two key laboratory species for studying sporulation are Myxococcus xanthus and Bacillus subtilis. Social behavior has long been considered an exceptional specialization of the myxobacteria, while B. subtilis has been considered a prototype of the single cell organism. Consequently, $B$. subtilis sporulation has traditionally been studied as an autonomous single cell event. That unicellular focus changed however, with the identification of two separate extracellular signals needed to initiate sporulation (Grossman \& Losick, 1988) and the discovery that wild type B. subtilis colonies contain morphologically distinct fruiting bodies where sporulation occurs (Branda et al., 2001). In addition to intercellular communication at the start of B. subtilis sporulation, another signaling system was discovered that controls programmed cell death of non-sporulating cells in the fruiting body at a later stage of the process (Gonzalez-Pastor et al., 2003). Analysis of sporulation-related signaling has revealed interlocking inter- and intracellular networks. These networks integrate cognitive inputs about external conditions, population structure and internal cell physiology so that cells may properly make the irreversible decision to undergo sporulation (Lazzazera \& Grossman, 1998).

Identifying intercellular signaling molecules has recently become a minor growth industry among microbiologists. Many of the molecules are labeled quorum sensors, based on the idea that they serve as population density monitors, and it is commonly believed that recognition of quorum sensing began in the 1980s (Fuqua et al., 1994). However, our knowledge of the role of intercellular population signals actually dates back to the 1960s and studies of extracellular 'competence factors' needed for bacteria to develop the ability to take up exogenous DNA in genetic transformation (Pakula \& Walczak, 1963). The fact that intercellular signaling was not recognized as a basic bacterial trait says more about our intellectual prejudices than about the status of experimental results. The nature of chemically characterised signaling molecules ranges from oligopeptides, proteins, amino acids, liposaccharides and fatty acids to aminoglycosides, acyl homoserine lactones and furanosyl borate diester. These chemically diverse signals affect properties as different as antibiotic production, exoenzyme synthesis, bioluminescence, symbiotic root nodulation, virulence, and group motility in addition to competence and sporulation (Shapiro, 1998; Waters \& Bassler, 2005). There is, therefore, a rich chemical vocabulary that bacteria use to control numerous multicellular traits. The role of multiple signaling molecules acting at different concentrations to regulate particular phenotypes is well documented in Vibrio and Pseudomonas (Henke \& Bassler, 2004; Soberon-Chavez et al., 2005; Venturi, 2006). The differences between the signals indicate that 
the syntax of this chemical language will prove far more intricate than simple, density dependent quorum sensing.

The use of diffusible signals is only one way that bacteria communicate. They also produce export and import structures that allow them to exchange genetic information and commandeer eukaryotic cells (Chen et al., 2005; Yip et al., 2005). These structures have been known since the earliest days of molecular biology because some of them (plasmid sex pili) are basic to much of bacterial genetics (Datta et al., 1966; Hayes, 1968). The ability to take over the processes of eukaryotic cells is especially relevant to a discussion of the informatic capacities of bacteria. Two well studied examples of these takeovers include Agrobacterium T-DNA transfer into plant nuclei to create tumor cells that feed the oncogenic bacterial population (McCullen \& Binns, 2006) and injection of proteins to reorganize mammalian host cell function and facilitate intracellular pathogensis (Mota \& Cornelis, 2005). The T-DNA encodes plant hormones that redirect growth control as well as biosynthetic enzymes that create compounds uniquely metabolized by Agrobacterium. The pathogen protein injection systems transfer molecules which disrupt signal transduction and cytoskeletal networks so that pathogenic bacteria, like Shigella dysenteriae, can enter epithelial cells, migrate between infected cells, and induce programmed cell death in lymphocytes that fight bacterial infections (Sansonneti, 2001). Based on examples such as these, one can confidently conclude that bacteria are master cell biologists and possess both the know-how and the technology they need to seize control of cell growth, metabolism and structure from the most highly developed multicellular organisms.

\section{A new paradigm for cells, genomes and evolution}

Since I began my own research career forty-two years ago, there has been a complete revolution in our understanding of how bacteria survive and reproduce. In the 1960 s we had no idea of the intricacy of molecular mechanisms for basic cellular processes, such as DNA replication, transcription, or cell division. For example, I have used a 1968 Scientific American article on DNA replication by Nobel Laureate Arthur Kornberg for teaching. In this early paper, Kornberg (1968) postulated that replication involved only a couple of proteins (polymerase and DNA ligase). He did not mention such basic features of the replication process as primers for initiating polymerization or the differences between copying leading and lagging strands, let alone the requirements for primases, helicases, topisomerases and clamps. Kornberg's article reflected the oversimplistic, reductionist thinking dominant in the first three decades of molecular biology that was based on mechanical, linear, sequential and unitary concepts of how biological systems operate. There was virtually no idea in the 1960s of ubiquitous multimolecular complexes or signal transduction networks. In genetics, pre-DNA ideas of genotype and phenotype dominated. Discussions of cognition, communication and computation were inconceivable.

Among the many strands of research that simultaneously enabled and demanded a reconceptualization, two are most relevant to my own experience. These are the studies of regulation initiated at the Institut Pasteur, where I had the good fortune to be a postdoctoral fellow, and the molecular study of transposable elements. The sequelae of Jacque Monod's discoveries about bacterial metabolism contain all the basic elements of transcriptional regulation and cellular signal transduction: cis-acting signals in DNA, allostery, receptors, protein phosphorylation, protein-protein interaction, nucleoprotein complexes and second messengers. The operator was the prototype of all the generic motifs in DNA that permit cells to carry out the basic functions of genome compaction, replication, transmission, expression and repair (Shapiro \& Sternberg, 2005). The molecular confirmation in bacteria (and later in eukaryotes) of McClintock's cytogenetic discoveries in maize revealed how inextricably multidirectional information transfer between the genome and the rest of the cell must be. Genomes contain sequences and encode molecules that cells use to restructure DNA for adaptive purposes, such as resource utilization, biocide resistance, and intercellular communication. We have learned enough to realize that how and when DNA restructuring occurs is a complex expression of linkages between signal transduction networks, natural genetic engineering functions and the genome.

The only way I know how to make sense out of the last fifty years of molecular biology is to abandon the mechanistic and atomistic ideas of the pre-DNA era and embrace a more organic, cognitive and computational view of cells and genomes. There are no units, only interactive systems. Bacteria continually pick up and process information about the environment, internal conditions and other cells to decide on appropriate biochemical and biomechanical actions. Comparisons to electronic information systems are useful because they allow us to think concretely and scientifically about complex information processing. For example, considering the genome a 'read-write' storage organelle rather than a 'read-only memory' frees us from the restrictions of arbitrary assumptions about the randomness of genomic change. This freedom will prove essential to understanding how intricate biological adaptations have evolved (Shapiro, 2005). However, we should not allow the electronic computation metaphor to become another intellectual straitjacket. Our digital electronic computing systems are far simpler than the distributed analog processors in living cells.

The take-home lesson of more than half a century of molecular microbiology is to recognize that bacterial information processing is far more powerful than human technology. The selected examples of bacterial 'smarts' I have given show convincingly that these small cells are incredibly sophisticated at coordinating processes involving millions of individual events and at making them precise and 
reliable. In addition, bacteria display astonishing versatility in managing the biosphere's geochemical and thermodynamic transformations: processes more complex than the largest human-engineered systems. This mastery over the biosphere indicates that we have a great deal to learn about chemistry, physics and evolution from our small, but very intelligent, prokaryotic relatives.

\section{References}

Adhya, S., \& Shapiro, J. A. (1969). The galactose operon of E. coli K-12. I: Structural and pleiotropic mutants of the operon. Genetics, 62, 231-248.

Adler, J. (1966). Chemotaxis in bacteria. Science, 153, 108-716.

Alberts, B., Johnson, A., Lewis, J., Raff, M., Roberts, K., \& Walter, P. (2002). Molecular biology of the cell (4th ed.). New York: Garland Publishing.

Aldridge, P., \& Hughes, K. T. (2002). Regulation of flagellar assembly. Current Opinion in Microbiology, 5, 160-165.

Avery, O. T., MacLeod, C. M., \& McCarty, M. (1944). Studies on the chemical nature of the substance inducing transformation of Pneumococcal types: Induction of transformation by a desoxyribonucleic acid fraction isolated prom Pneumococcus Type III. Journal of Experimental Medicine, 79, 137-158.

Barbour, A. G., Carter, C. J., \& Sohaskey, C. D. (2000). Surface protein variation by expression site switching in the relapsing fever agent Borrelia hermsii. Infection and Immunity, 68, 7114-7121.

Blomfield, I. C. (2001). The regulation of pap and type 1 fimbriation in Escherichia coli. Advances in Microbial Physiology, 45, 1-49.

Branda, S. S., Gonzalez-Pastor, J. E., Ben-Yehuda, S., Losick, R., \& Kolter, R. (2001). Fruiting body formation by Bacillus subtilis. Proceedings of the National Academy of Sciences, USA, 98, 11621-11626.

Branda, S. S., Vik, S., Friedman, L., \& Kolter, R. (2005). Biofilms: The matrix revisited. Trends in Microbiology, 13, 20-26.

Bray, D. (1990). Intracellular signalling as a parallel distributed process. Journal of Theoretical Biology, 143, 215-231.

Bray, D. (1995). Protein molecules as computational elements in living cells. Nature, 376, 307-312.

Bray, D. (2002). Bacterial chemotaxis and the question of gain. Proceedings of the National Academy of Sciences, USA, 99, 7-9.

Bray, D., Bourret, R. B., \& Simon, M. I. (1993). Computer simulation of the phosphorylation cascade controlling bacterial chemotaxis. Molecular Biology of the Cell, 4, 469-482.

Bukhari, A. I., Shapiro, J. A., \& Adhya, S. L. (Eds.). (1977). DNA insertion elements, plasmids and episomes. Cold Spring Harbor, New York: Cold Spring Harbor Press.

Campbell, A. (1962). Episomes. Advances in Genetics, 11, 101-145.

Casadaban, M. J. (1976). Transposition and fusion of the lac genes to selected promoters in Escherichia coli using bacteriophage lambda and $\mathrm{Mu}$. Journal of Molecular Biology, 104, 541-555.

Chen, I., Christie, P. J., \& Dubnau, D. (2005). The ins and outs of DNA transfer in bacteria. Science, 310, 1456-1460.

Cohen, S. N., \& Shapiro, J. A. (1980). Transposable genetic elements. Scientific American, 242(2), 40-49.

Cooper, S., \& Helmstetter, C. E. (1968). Chromosome replication and the division cycle of Escherichia coli B/r. Journal of Molecular Biology, 31, 519-540.

Costerton, J. W., Stewart, P. S., \& Greenberg, E. P. (1999). Bacterial biofilms: A common cause of persistent infections. Science, 284, 1318-1322.

Craig, N. L., Craigie, R., Gellert, M., \& Lambowitz, A. M. (2002). Mobile DNA II. Washington, DC: American Society of Microbiology Press.

Datta, N., Lawn, A. M., \& Meynell, E. (1966). The relationship of F type piliation and $\mathrm{F}$ phage sensitivity to drug resistance transfer in $\mathrm{R}+\mathrm{F}$ Escherichia coli K 12. Journal of General Microbiology, 45, 365-376.
Davies, D. (2003). Understanding biofilm resistance to antibacterial agents. Nature Reviews Drug Discovery, 2, 114-122.

Dobrindt, U., Hochhut, B., Hentschel, U., \& Hacker, J. (2004). Genomic islands in pathogenic and environmental microorganisms. Nature Reviews Microbiology, 2, 414-424.

Doulatov, S., Hodes, A., Dai, L., Mandhana, N., Liu, M., Deora, R., Simons, R. W., Zimmerly, S., \& Miller, J. F. (2004). Tropism switching in Bordetella bacteriophage defines a family of diversity-generating retroelements. Nature, 431, 476-481.

Dworkin, M. (1962). Nutritional requirements for vegetative growth of Myxococcus xanthus. The Journal of Bacteriology, 84, 250-257.

Dworkin, M. (1983). Tactic behavior of Myxococcus xanthus. The Journal of Bacteriology, 154, 452-459.

Dworkin, M. (2000). Introduction to the myxobacteria. In Y. V. Brun, \& L. Shimkets (Eds.), Prokaryotic Development (pp. 221-242). Washington, DC: American Society of Microbiology.

Embley, T. M., \& Martin, W. (2006). Eukaryotic evolution, changes and challenges. Nature, 440, 623-630.

Esipov, S., \& Shapiro, J. A. (1998). Kinetic model of Proteus mirabilis swarm colony development. Journal of Mathematical Biology, 36, 249-268.

Foster, T. J. (1983). Plasmid-determined resistance to antimicrobial drugs and toxic metal ions in bacteria. Microbiology Reviews, 47, 361-409.

Fuqua, W. C., Winans, S. C., \& Greenberg, E. P. (1994). Quorum sensing in bacteria: The LuxR-LuxI family of cell density-responsive transcriptional regulators. The Journal of Bacteriology, 176, 269-275.

Gerhart, J., \& Kirschner, M. (1997). Cells, embryos, and evolution. Malden: Blackwell Science.

Gonzalez-Pastor, J. E., Hobbs, E. C., \& Losick, R. (2003). Cannibalism by sporulating bacteria. Science, 301, 510-513.

Gray, M. W. (1999). Evolution of organellar genomes. Current Opinion in Genetics and Development, 9, 678-687.

Grossman, A. D., \& Losick, R. (1988). Extracellular control of spore formation in Bacillus subtilis. Proceedings of the National Academy of Sciences, USA, 85, 4369-4373.

Gupta, R. S. (1998). Protein phylogenies and signature sequences: A reappraisal of evolutionary relationships among archaebacteria, eubacteria, and eukaryotes. Microbiology and Molecular Biology Reviews, 62, 1435-1491.

Gupta, R. S. (2000). The phylogeny of proteobacteria: Relationships to other eubacterial phyla and eukaryotes. FEMS Microbiology Reviews, 24, 367-402.

Gyohda, A., Furuya, N., Ishiwa, A., Zhu, S., \& Komano, T. (2004). Structure and function of the shufflon in plasmid R64. Advances in Biophysics, 38, 183-213.

Hall, B. G. (1998). Activation of the $b g l$ operon by adaptive mutation. Molecular Biology and Evolution, 15, 1-5.

Hall, B. G. (1999). Spectra of spontaneous growth-dependent and adaptive mutations at ebgR. The Journal of Bacteriology, 181, $1149-1155$.

Hall, R. M., \& Collis, C. M. (1995). Mobile gene cassettes and integrons: Capture and spread of genes by site-specific recombination. Molecular Microbiology, 15, 593-600.

Hayes, W. (1968). The genetics of bacteria and their viruses. London: Blackwell.

Henke, J. M., \& Bassler, B. L. (2004). Three parallel quorum-sensing systems regulate gene expression in Vibrio harveyi. The Journal of Bacteriology, 186, 6902-6914.

Hoffmeister, M., \& Martin, W. (2003). Interspecific evolution: Microbial symbiosis, endosymbiosis and gene transfer. Environmental Microbiology, 5, 641-649.

Holmes, A. J., Gillings, M. R., Nield, B. S., Mabbutt, B. C., Nevalainen, K. M. H., \& Stokes, H. W. (2003). The gene cassette metagenome is a basic resource for bacterial genome evolution. Environmental Microbiology, 5, 383-394.

Hõrak, R., Ilves, H., Pruunsild, P., Kuljus, M., \& Kivisaar, M. (2004). The ColR-ColS two-component signal transduction system is involved in 
regulation of Tn4652 transposition in Pseudomonas putida under starvation conditions. Molecular Microbiology, 54, 795-807.

Horiike, T., Hamada, K., Kanaya, S., \& Shinozawa, T. (2001). Origin of eukaryotic cell nuclei by symbiosis of Archaea in Bacteria revealed is revealed by homology hit analysis. Nature Cell Biology, $3,210-214$.

Horiike, T., Hamada, K., Miyata, D., \& Shinozawa, T. (2004). The origin of eukaryotes is suggested as the symbiosis of pyrococcus into gammaproteobacteria by phylogenetic tree based on gene content. Journal of Molecular Evolution, 59, 606-619.

Ilves, H., Hõrak, R., \& Kivisaar, M. (2001). Involvement of sigma (S) in starvation-induced transposition of Pseudomonas putida transposon Tn4652. The Journal of Bacteriology, 183, 5445-5448.

Jacob, F., \& Monod, J. (1961). Genetic regulatory mechanisms in the synthesis of proteins. Journal of Molecular Biology, 3, 318-356.

Judson, H. F. (1979). The eighth day of creation: The makers of the revolution in biology. New York: Simon and Schuster.

Kaiser, D. (1993). Roland Thaxter's legacy and the origins of multicellular development. Genetics, 135, 249-254.

Kornberg, A. (1968). The synthesis of DNA. Scientific American, 219(4), 64-78.

Koshland, D. (1980). Bacterial chemotaxis as a model behavioral system. Distinguished Lecture Series of the Society of General Physiologists (Vol. 2). London: Raven Press Ltd.

Kuhn, T. (1962). The structure of scientific revolutions. Chicago: University of Chicago Press.

Kunkel, T. A., \& Bebenek, K. (2000). DNA replication fidelity. Annual Review of Biochemistry, 69, 497-529.

Lamrani, S., Ranquet, C., Gama, M.-J., Nakai, H., Shapiro, J. A., Toussaint, A., \& Maenhaut-Michel, G. (1999). Starvation-induced Mucts62-mediated Coding Sequence Fusion: Roles for ClpXP, Lon, RpoS and Crp. Molecular Microbiology, 32, 327-343.

Lazazzera, B. A., \& Grossman, A. D. (1998). The ins and outs of peptide signaling. Trends in Microbiology, 6, 288-294.

Lenton, T. M., \& van Oijen, M. (2002). Gaia as a complex adaptive system. Philosophical Transactions of the Royal Society of London B. Biological Sciences, 357, 683-695.

Lovelock, J. E., \& Margulis, L. (1974). Homeostatic tendencies of the earth's atmosphere. Origins of Life and Evolution of Biospheres, 5, 93-103.

Luisi, P. L., Ferri, F., \& Stano, P. (2006). Approaches to semi-synthetic minimal cells: A review. Naturwissenschaften, 93, 1-13.

MacDonald, D., Demarre, G., Bouvier, M., Mazel, D., \& Gopaul, D. N. (2006). Structural basis for broad DNA-specificity in integron recombination. Nature, 440, 1157-1162.

Maenhaut-Michel, G., \& Shapiro, J. A. (1994). The roles of starvation and selective substrates in the emergence of araB-lacZ fusion clones. EMBO Journal, 13, 5229-5239.

Mahillon, J., \& Chandler, M. (1998). Insertion sequences. Microbiology and Molecular Biology Reviews, 62, 725-774.

Margulis, L., Dolan, M. F., \& Guerrero, R. (2000). The chimeric eukaryote: Origin of the nucleus from the karyomastigont in amitochondriate protists. Proceedings of the National Academy of Sciences, USA, 97, 6954-6959.

Mazel, D., Dychinco, B., Webb, V. A., \& Davies, J. (1998). A distinctive class of integron in the Vibrio cholerae genome. Science, 280, 605-608.

McClintock, B. (1984). Significance of responses of the genome to challenge. Science, 226, 792-801.

McClintock, B. (1987). Discovery and characterization of transposable elements: The collected papers of Barbara McClintock. New York: Garland.

McCullen, C. A., \& Binns, A. N. (2006). Agrobacterium tumefaciens plant cell interactions and activities required for interkingdom macromolecular transfer. Annual Review of Cell and Developmental Biology, 22, $101-127$.

Meibom, K. L., Blokesch, M., Dolganov, N. A., Wu, C-Y., \& Schoolnik, G. K. (2005). Chitin induces natural competence in Vibrio cholerae. Science, 310, 1824-1827.
Meynell, E., \& Datta, N. (1967). Mutant drug resistant factors of high transmissibility. Nature, 214, 885-887.

Modrich, P. (1991). Mechanisms and biological effects of mismatch repair. Annual Review of Genetics, 25, 229-253.

Mohr, G., Smith, D., Belfort, M., \& Lambowitz, A. M. (2000). Rules for DNA target-site recognition by a lactococcal group II intron enable retargeting of the intron to specific DNA sequences. Genes and Development, 14, 559-573.

Monod, J. (1942). Recherches sur la croissance des cellules bactériennes. Ph.D. thesis. Actualités scientifiques et industrielles. Paris: Hermann.

Mota, L. J., \& Cornelis, G. R. (2005). The bacterial injection kit: Type III secretion systems. Annals of Medicine, 37, 234-249.

Newton, W. A., Beckwith, J. R., Zipser, D., \& Brenner, S. (1965). Nonsense mutants and polarity in the lac operon of Escherichia coli. Journal of Molecular Biology, 14, 290-296.

Osborn, A. M., \& Boltner, D. (2002). When phage, plasmids, and transposons collide: Genomic islands, and conjugative- and mobilizable-transposons as a mosaic continuum. Plasmid, 48, 202-212.

Pakula, R., \& Walczak, W. (1963). On the nature of competence of transformable streptococci. Journal of General Microbiology, 31, $125-133$.

Parsek, M. R., \& Fuqua, C. (2004). Biofilms 2003: Emerging themes and challenges in studies of surface-associated microbial life. The Journal of Bacteriology, 186, 4427-4440.

Radman, M., \& Wagner, R. (1988). The high fidelity of DNA duplication. Scientific American, 259(2), 40-46.

Rauprich, O., Matsushita, M., Weijer, K., Siegert, F., Esipov, S., \& Shapiro, J. A. (1996). Periodic phenomena in Proteus mirabilis swarm colony development. The Journal of Bacteriology, 178, 6525-6538.

Rivera, M. C., \& Lake, J. A. (2004). The ring of life provides evidence for a genome fusion origin of eukaryotes. Nature, 431, 152-155.

Rosenberg, S. M. (2001). Evolving responsively: Adaptive mutation. Nature Reviews, Genetics, 2, 504-515.

Sansonetti, P. J. (2001). Rupture, invasion and inflammatory destruction of the intestinal barrier by Shigella: Making sense of prokaryoteeukaryote cross-talks. FEMS Microbiology Reviews, 25, 3-14.

Saunders, N. J., Jeffries, A. C., Peden, J. F., Hood, D. W., Tettelin, H., Rappuoli, R., \& Moxon, E. R. (2000). Repeat-associated phase variable genes in the complete genome sequence of Neisseria meningitidis strain MC58. Molecular Microbiology, 37, 207-215.

Schink, B. (2002). Synergistic interactions in the microbial world. Antonie Van Leeuwenhoek, 81, 257-261.

Shapiro, J. A. (1968). The structure of the galactose operon in Escherichia coli $K-12$. Ph.D. thesis, University of Cambridge.

Shapiro, J. A. (1969). Mutations caused by the insertion of genetic material into the galactose operon of Escherichia coli. Journal of Molecular Biology, 40, 93-105.

Shapiro, J. (1979). A molecular model for the transposition and replication of bacteriophage $\mathrm{Mu}$ and other transposable elements. Proceedings of the National Academy of Sciences, USA, 76, 1933-1937.

Shapiro, J. A. (1983). Mobile genetic elements. New York: Academic Press.

Shapiro, J. A. (1984a). Observations on the formation of clones containing araB-lacZ cistron fusions. Molecular and General Genetics, 194, 79-90.

Shapiro, J. A. (1984b). Transposable elements, genome reorganization and cellular differentiation in Gram-negative bacteria. Symposium of the Society for General Microbiology, 36(2), 169-193.

Shapiro, J. A. (1984c). The use of Mudlac transposons as tools for vital staining to visualize clonal and non-clonal patterns of organization in bacterial growth on agar surfaces. Journal of General Microbiology, 130, 1169-1181.

Shapiro, J. A. (1987). Organization of developing E. coli colonies viewed by scanning electron microscopy. The Journal of Bacteriology, 197, 142-156.

Shapiro, J. A. (1988). Bacteria as multicellular organisms. Scientific American, 256(6), 82-89.

Shapiro, J. A. (1992a). Natural genetic engineering in evolution. Genetica, 86, 99-111. 
Shapiro, J. A. (1992b). Concentric rings in Escherichia coli colonies. In L. Rensing (Ed.), Oscillations and morphogenesis (pp. 297-310). Marcell Dekker.

Shapiro, J. A. (1992c). Kernels and colonies: The challenge of pattern. In N. Federoff, \& D. Botstein (Eds.), The dynamic genome (pp. 213-221). Cold Spring Harbor Laboratory Press.

Shapiro, J. A. (1997). Genome organization, natural genetic engineering and adaptive mutation. Trends in Genetics, 13, 98-104.

Shapiro, J. A. (1998). Thinking about bacterial populations as multicellular organisms. Annual Review of Microbiology, 52, 81-104.

Shapiro, J. A. (2002a). A 21st Century view of evolution. Journal of Biological Physics, 28, 745-764.

Shapiro, J. A. (2002b). Repetitive DNA, genome system architecture and genome reorganization. Research in Microbiology, 153, $447-453$.

Shapiro, J. A. (2002c). Repetitive DNA, genome system architecture and genome reorganization. Research in Microbiology, 153, 447-453.

Shapiro, J. A. (2005). A 21 st century view of evolution: Genome system architecture, repetitive DNA, and natural genetic engineering. Gene, $345,91-100$.

Shapiro, J. A., \& Adhya, S. (1969). The galactose operon of E. coli K-12. II: A deletion analysis of operon structure and polarity. Genetics, 62, 249.

Shapiro, J. A., \& Dworkin, M. (Eds.). (1997). Bacteria as multicellular organisms. New York: Oxford University Press.

Shapiro, J. A., \& Higgins, N. P. (1989). Differential activity of a transposable element in E. coli colonies. The Journal of Bacteriology, 171, 5975-5986.

Shapiro, J. A., \& Hsu, C. (1989). E. coli K-12 cell-cell interactions seen by time-lapse video. The Journal of Bacteriology, 171, 5963-5974.

Shapiro, J. A., MacHattie, L., Eron, L., Ihler, G., Ippen, K., Beckwith, J., Arditti, R., Reznikoff, W., \& MacGillivray, R. (1969). The isolation of pure lac operon DNA. Nature, 224, 768-774.

Shapiro, J. A., \& Sternberg, R. V. (2005). Why repetitive DNA is essential for genome function. Biological Reviews, 80, 227-250.

Soberon-Chavez, G., Aguirre-Ramirez, M., \& Ordonez, L. (2005). Is Pseudomonas aeruginosa only "sensing quorum"? Critical Reviews in Microbiology, 31, 171-182.

Sonea, S., \& Mathieu, L. G. (2001). Evolution of the genomic systems of prokaryotes and its momentous consequences. International Microbiology, 4, 67-71.
Sonea, S., \& Panisset, M. (1983). A new bacteriology. Boston: Jones and Bartlett.

Spiegelman, D., Whissell, G., \& Greer, C. W. (2005). A survey of the methods for the characterization of microbial consortia and communities. Canadian Journal of Microbiology, 51, 355-386.

Stoodley, P., Sauer, K., Davies, D. G., \& Costerton, J. W. (2002). Biofilms as complex differentiated communities. Annual Review of Microbiology, 56, 187-209.

Sutton, M. D., Smith, B. T., Godoy, V. G., \& Walker, G. C. (2000). The SOS response: Recent insights into umuDC-dependent mutagenesis and DNA damage tolerance. Annual Review of Genetics, 34, 479-497.

Toussaint, A., Gama, M. J., Laachouch, J., Maenhaut-Michel, G., \& Mhammedi-Alaoui, A. (1994). Regulation of bacteriophage $\mathrm{Mu}$ transposition. Genetica, 93, 27-39.

Ullrich, S., Kube, M., Schubbe, S., Reinhardt, R., \& Schuler, D. (2005). A hypervariable 130-kilobase genomic region of Magnetospirillum gryphiswaldense comprises a magnetosome island which undergoes frequent rearrangements during stationary growth. The Journal of Bacteriology, 187, 7176-7184.

Venturi, V. (2006). Regulation of quorum sensing in Pseudomonas. FEMS Microbiol. Reviews, 30, 274-291.

Watanabe, T. (1963). Infective heredity of multiple drug resistance in bacteria. Bacteriology Review, 27, 87-115.

Waters, C. M., \& Bassler, B. L. (2005). Quorum sensing: Cell-to-cell communication in bacteria. Annual Review of Cell and Developmental Biology, 21, 319-346.

Webb, J. S., Givskov, M., \& Kjelleberg, S. (2003). Bacterial biofilms: Prokaryotic adventures in multicellularity. Current Opinion in Microbiology, 6, 578-585.

Weinert, T. A., \& Hartwell, L. H. (1993). Cell cycle arrest of cdc mutants and specificity of the RAD9 checkpoint. Genetics, 134, 63-80.

Wessler, S. R. (1996). Turned on by stress: Plant retrotransposons. Current Biology, 6, 959-961.

Witkin, E. M. (1991). RecA protein in the SOS response: ilestones and mysteries. Biochimie, 73, 133-141.

Yip, C. K., Finlay, B. B., \& Strynadka, N. C. (2005). Structural characterization of a type III secretion system filament protein in complex with its chaperone. Nature Structure and Molecular Biology, $12,75-81$.

Zieg, J., Silverman, M., Hilmen, M., \& Simon, M. (1977). Recombinational switch for gene expression. Science, 196, 170-172. 